\title{
Prescription patterns and adequacy of blood pressure control among adult hypertensive patients in Kenya; findings and implications
}

\author{
JENNIFER M. MBUI ${ }^{1}$, MARGARET N. OLUKA ${ }^{1}$, ERIC M. GUANTAII ${ }^{1}$ KIPRUTO A. SINEI ${ }^{1}$, LOICE \\ ACHIENG ${ }^{2}$, AMANJ BAKER ${ }^{3}$, MARY JANDE ${ }^{4}$, AMOS MASSELE ${ }^{5}$, *BRIAN GODMAN ${ }^{3,6,7}$
}

\begin{abstract}
1Department of Pharmacology and Pharmacognosy, School of Pharmacy, University of Nairobi, P.O Box 19676-00202, Nairobi, Kenya. Email: mbuijennifer@gmail.com; olukamarga@yahoo.com, eguantai@uonbi.ac.ke; sinei@uonbi.ac.ke

2Department of Medicine, University of Nairobi, Nairobi, Kenya. Email: loicea.la@gmail.com

${ }^{3}$ Strathclyde Institute of Pharmacy and Biomedical Sciences, Strathclyde University, Glasgow, UK.

Emails: Brian.godman@strath.ac.uk; amanj.baker@strath.ac.uk

${ }^{4}$ School of Pharmacy, Catholic University of Health and Allied Science, P.O. Box 1464, Mwanza,

Tanzania. Emails: maryjande@gmail.com

${ }^{5}$ Department of Clinical Pharmacology, School of Medicine, University of Botswana, Gaborone,

Botswana. Email: amos.massele@mopipi.ub.bw

${ }^{6}$ Department of Laboratory Medicine, Division of Clinical Pharmacology, Karolinska Institutet, Karolinska University Hospital Huddinge, Stockholm, Sweden. Email: Brian.Godman@ki.se

${ }^{7}$ Health Economics Centre, Liverpool University Management School, Liverpool University, UK. Email:

Brian.Godman@liverpool.ac.uk
\end{abstract}

\begin{abstract}
*Author for correspondence. Division of Clinical Pharmacology, Karolinska Institute, Karolinska University Hospital Huddinge, SE-141 86, Stockholm, Sweden. Email: Brian.Godman@ki.se. Telephone + 46858581068 . Fax + 46859581070 and Strathclyde Institute of Pharmacy and Biomedical Sciences, University of Strathclyde, Glasgow G4 ORE, United Kingdom. Email: brian.godman@strath.ac.uk. Telephone: 0141548 3825. Fax: 01415522562
\end{abstract}

(Accepted for publication - Expert Review of Clinical Pharmacology. Please keep CONFIDENTIAL).

\section{ABSTRACT}

Introduction: Hypertension is a major cause of global morbidity and mortality, with high prevalence rates in Africa including Kenya. Consequently, it is imperative to understand current treatment approaches and their effectiveness in practice. Currently, there is paucity of such data in Kenya, which is a concern. The aim is to describe prescribing patterns and adequacy of blood pressure control in adult hypertensive patients to guide future practice. Method: Retrospective study of patients attending a sub-county outpatient clinic combined with qualitative interviews. Results: 247 hypertensive patients, predominantly female, mean age 55.8 years on antihypertensive therapy for $1-5$ years, were analyzed. ACEls and thiazide diuretics were the most commonly prescribed mainly as combination therapy. Treatment typically complied with guidelines, mainly for stage 2 hypertension (75\%). BP control was observed in $46 \%$ of patients, with a significant reduction in mean systolic (155 to $144 \mathrm{mmHg}$ ) and diastolic (91 to 83 $\mathrm{mmHg}) \mathrm{BP}(\mathrm{P}<0.001)$. Patients on $\geq 2$ antihypertensive drugs were more likely to have uncontrolled $\mathrm{BP}$ (OR:1.9, $p=0.021$ ). Conclusion: Encouragingly good adherence to guidelines helped by training. Poor blood pressure control in the majority needs to be addressed. Additional training of prescribers and follow-up of measures to improve BP control will be introduced and followed up.

Key words: Hypertension, Prescribing patterns, treatment guidelines, antihypertensive medicines, Kenya

\section{INTRODUCTION}

The highest prevalence of hypertension worldwide is seen in the African region (1), with reported prevalence as high as $80 \%$ among those aged 50 or over $(2,3)$, which is set to rise (1), enhanced by growing rates of diabetes and obesity $(4,5)$. High rates are not helped by typically low levels of awareness, treatment, and control of hypertension among patients in Africa, including Kenya, exacerbated by low levels of medication adherence $(1,6,7)$. In Kenya, the mean systolic blood pressure has increased from 127 to $132 \mathrm{mmHg}$ between 1990 and 2008 (8). Overall prevalence rates of hypertension among adults in Kenya aged between 35 and 64 is approximately $30 \%$ (7). However, others have demonstrated higher rates of $50 \%$ or more $(9,10)$. Consequently, hypertension has emerged as a major global public health issue in Africa $(11,12)$ including Kenya. 
Antihypertensive therapy has demonstrated clear benefits through reducing the risk of adverse health outcomes (13). The use of treatment guidelines typically enhances the appropriate use of medicines, although there are concerns with adherence rates to guidelines in practice across countries (14-18). The current Kenyan Standard Treatment Guidelines (STGs) recommend the use of diuretics, beta blockers, calcium channel blockers (CCDs), angiotensin converting enzyme inhibitors (ACEIs) and angiotensin receptor blockers (ARBs) for patients with hypertension. This is in line with Joint National Committee (JNC) Guidelines $(19,20)$, with treatment subsequently stepped up if blood pressure (BP) control is not being achieved. However, there is stronger recommendation of a thiazide diuretic or a CCB initially in the JNC guidelines $(19,20)$ compared with the Kenyan STGs, which recommend ACEls as first line therapy (21), potentially leading to under use of CCBs in Kenya

To date, there is paucity of data on prescribing patterns of antihypertensive medicines in Kenya. This is a matter of concern considering the public health burden of hypertension in Kenya, and the serious patient consequences of poor control $(1,8,10,22)$. In addition, the few studies to date have typically found only limited control of hypertension in Kenya, even in those patients taking anti-hypertensive medicines (23), at rates ranging from $3 \%$ to $33 \%$ of the adult population $(9,23-25)$.

Consequently, we sought to ascertain current prescribing patterns of antihypertensive medicines in patients undergoing treatment for hypertension in Kenya, determine the level of compliance with treatment guidelines and subsequent adequacy of BP control, as well as identify key determinants of BP control among adult hypertensive patients. The findings to provide future guidance to the Ministry of Health, and other authorities in Kenya, to improve future control of hypertension.

Currently, there is also a scarcity of electronic health information systems in Kenya to monitor the care of patients in ambulatory care, unlike the situation for these patients with HIV included in the AMPATH programme; however, initiatives are in place to address this (26-30). The introduction of Access programmes to improve the availability of medicines to patients with chronic diseases in Kenya, such as those with hypertension, should further help in the development of such systems $(31,32)$ to address recognized deficiencies (33). As a result, the findings from this study can also be used as a baseline to further improve the management of this important disease as access to medicines improves for patients

\section{Materials and Methods}

\subsection{Study locality}

The study was conducted at the medical out-patient clinic (MOPC) of Ruiru sub-county hospital in Kiambu County, Kenya. Ruiru is one of the peri-urban satellite towns of Nairobi City with a community of mainly middle class socioeconomic status. The MOPC serves approximately 800 active hypertensive patients from both urban and rural areas. Prescribers at the MOPC consist of medical consultants, medical officers and clinical officers. Consequently, this can provide a reasonable representation of current treatment practices across MOPCs in Kenya. In addition, provide a baseline for the recent access programmes, with this MOPC one of the chosen sites.

\subsection{Study design}

A descriptive cross-sectional study was conducted between January to April 2015 to collect data on the current use of antihypertensive medicines and their rationale at the MOPC of Ruiru Sub-county hospital. A mixed-method approach was used to collect data whereby quantitative data were collected by retrospective analysis of medicines prescribed from patients' medical records at their last visit using a pre-designed and validated data collection form. A semi-structured interview guide was used for collecting qualitative data from prescribers at the MOPC, pre-tested to enhance the quality of data collection. Its content is described below.

\subsection{Study population}

The study population consisted of active, registered hypertensive patients aged 18 years and above, attending the MOPC at Ruiru Sub-County hospital for at least one year prior to the commencement of the study. The patients were on treatment with at least one anti-hypertensive medicine, had visited the clinic at least three times in the year preceding the study period (January to April 2015) to demonstrate they had received routine management and had complete medical records. Hypertensive patients were excluded if they had not visited the clinic at least three times in a year, were pregnant or had incomplete medical records. This is because it is normal practice in this clinic to review patients at least every three 
to four months. The one year follow-up period was deemed adequate to provide enough treatment record to evaluate the management of hypertension at this facility. For the qualitative study, the study population consisted of all prescribers stationed at the MOPC at the time of the study.

\subsection{Sample size}

The sample size for this study was calculated according to the Cochran formula for sample size calculation for categorical variables (34). A previous study in Kenya had reported compliance to antihypertensive guidelines of $80 \%(35)$, which was used in sample size calculation as follows: $n=z^{2}$ (p) (q)/d2. Where:

$\mathrm{n}=$ sample size

$z=z$ statistic for $95 \%$ level of confidence which is conventionally $=1.96$

$p=$ estimated prevalence or proportion in the population

$q=1-p$

$d=$ level of precision used in the study set at $5 \%$

A sample size of 246 was calculated from the above formula which was adjusted to cater for the proportion of files with incomplete data estimated at $10 \%$ to yield a sample size of 271 .

\subsection{Sampling procedure}

Systematic purposive sampling was used to sample patients from a list of patients obtained from the patient attendance register for every clinic day of the four-month study period. Files belonging to the eligible sampled patients were retrieved from the records department until the required sample size was accrued. Informed consent was obtained from the prescribers before enrolment into the study. Since only five prescribers were working at the MOPC during the period of data collection, all were interviewed.

\subsection{Data collection procedure}

A predesigned, validated data collection form was used to abstract quantitative data from the medical records of each patient. Data were collected on the following at recruitment into the study: patient demographic characteristics, comorbidities, BP, current antihypertensive medication and other concurrent medications as recorded in each patient's file at the last visit during the study period. In addition, the initial BP reading when the patient was registered at the clinic was determined retrospectively from the patient records and recorded.

At Ruiru sub-county hospital, initial and subsequent blood pressure (BP) was typically recorded using a digital sphygmomanometer, and co-morbidities such as diabetes (defined as blood glucose $>7.8$ $\mathrm{mmol} / \mathrm{L}$ on more than one occasion) were diagnosed as per the Kenyan STGs for the management and referral of common conditions (21). This information was typically recorded in the patients' notes and subsequently transferred to the data collection forms for analysis. There was no other source of clinical information.

For the qualitative study, prescribers working at the study site were informed about the study including the expected duration of the interview, voluntary participation and confidentiality. On signing the consent form, the interview was conducted using a semi-structured interview guide. Data collected included prescribers' cadre; approximate number of patients seen per clinic day (workload); awareness and adherence to treatment guidelines for hypertension; post-qualification training on the use of the guidelines; challenges encountered in their management of hypertensive patients; and barriers to their adherence to treatment guidelines.

\subsection{Data analysis}

Quantitative data were analysed using STATA 10 (StanCorp, Inc, Texas, and USA). All data were subjected to descriptive data analysis. Continuous variables were presented as means (SD) when normally distributed and as median (range) when not normally distributed. Categorical variables were presented as counts and percentages. Antihypertensive medicines were categorized according to their therapeutic classes. The frequency of each pharmacological class and that of individual medications were expressed as a percentage of the total number of prescriptions. Patients were categorized according to the levels of their systolic blood pressure (SBP) and diastolic blood pressure (DBP) at diagnosis and at the last visit according to the JNC-7 classification of hypertension (19) (Box 1). 
Box 1 - Grades of hypertension according to the JNC-7 classification of hypertension

\begin{tabular}{|lll|}
\hline \multicolumn{1}{|c|}{ Grades of hypertension } & SBP $(\mathrm{mmHg})$ & $\mathrm{DBP}(\mathrm{mmHg})$ \\
\hline Normal BP & $<120$ & \\
Prehypertension & $120-139$ & $80-89$ \\
Stage 1 & $140-159$ & $90-99$ \\
Stage 2 & $\geq 160$ & $\geq 100$ \\
Isolated systolic hypertension & $\geq 140$ & $<90$ \\
& & \\
\hline
\end{tabular}

NB:SBP = systolic blood pressure, DBP = diastolic blood pressure

Patients were also grouped according to the adequacy of their BP control. Adequate BP control was defined as having the most recent reading of less than $140 / 90 \mathrm{mmHg}$ in line with WHO guidance $(1,5)$. Bivariate analysis was done to compare subjects with controlled and those with un-controlled BP. Comparison of the distribution of variables across arms was done by Pearson chi-square test for categorical variables, or the unpaired t-test for continuous variables. Variables that were found significant in the bivariate analysis were then included in a multivariable logistic regression analysis to identify key independent variables influencing BP control. P-values of 0.05 or less were considered as significant.

Prescription patterns for treatment of hypertension at the study site were subsequently compared to both the JNC-8 management guidelines and the Kenyan STGs (21). However, for evaluating adherence, comparisons were undertaken to JNC 8 guidelines. JNC 8 guidelines were chosen as they were the most current, evidence-based guidelines at the time of the study, and represented a credible international benchmark for the management of hypertension. They were seen as more up-to-date than the Kenyan STGs, and gave specifications on black patients, with the Kenyan STGs last revised in 2009. For example, the Kenyan STG recommends the use of an ACEI in diabetic -hypertensive patients. However, recent studies have failed to show the superiority of ACEls over other treatments in the prevention of renal disease among black patients (36), reflected in JNC 8, which recommends the use of thiazide diuretics or CCBs as first-line therapy in black patients $(19,20)$. JNC8 is also seen as more relevant to Kenya than for instance NICE, ESH or CHEP recommendations in view of its comments on treating black hypertensive patients alongside being seen as more up-to-date $(37,38)$, The criteria for evaluation focused on choices of prescribed drugs, appropriate drug therapy for compelling indications, appropriate concurrent drugs and appropriate combination therapy and dosing.

A qualitative review of interview responses was carried out through a descriptive analysis of key data from each participant. Analysis was undertaken by discerning patterns or themes among responses from participants and performing meaningful groupings of the themes.

\subsection{Ethical consideration}

Approval to carry out the study was granted by the Kenyatta National Hospital / University of Nairobi Ethics Review Committee (KNH/UoN ERC). Approval to conduct the study was also granted by the Hospital management. Patient records were identified by codes to maintain privacy and confidentiality. Informed consent was granted by all prescribers from whom qualitative data was collected.

\section{Results}

\subsection{Baseline characteristics of study population}

Baseline characteristics of study population are shown in Table 1. A total of 247 hypertensive patients were included in the study of which the majority, $216(87 \%)$, were females. The overall mean age of the hypertensive patients was $56 \pm 12.5$ years, with most of the patients being in the range of 40 to 59 years $(44 \%)$. Diabetes was the most common comorbidity among the hypertensive patients (37\%). Most of the patients $178(72 \%)$ had been on antihypertensive therapy for between one and five years. 
Table 1: Baseline characteristics of hypertensive patients included in the study ( $\mathrm{N}=247)$

\begin{tabular}{lll}
\hline Characteristics & $\mathbf{n}$ & $\mathbf{\%}$ \\
\hline Sex & 31 & \\
$\quad$ Male & 216 & 12.6 \\
$\quad$ Female & & 87.4 \\
Age (years) & 28 & \\
$\quad 20-39$ & 109 & 11.3 \\
$40-59$ & 107 & 44.1 \\
$60-79$ & 3 & 43.3 \\
$\quad \geq 80$ & & 1.2 \\
Comorbid conditions & 91 & \\
$\quad$ Diabetes & 5 & 36.8 \\
Cardiovascular disease & 6 & 2.0 \\
Peripheral neuropathy & 4 & 2.4 \\
Asthma & 1 & 1.6 \\
HIV/AIDS & 1 & 0.4 \\
Arthritis & 139 & 0.4 \\
$\quad$ None & & 56.2 \\
Treatment duration & 63 & \\
$\quad \leq 1$ year & 178 & 25.5 \\
$\quad>1$ to 5 years & 4 & 72.1 \\
>5 to 10 years & 2 & 1.6 \\
>10 years & & 0.8 \\
\hline
\end{tabular}

\subsection{Prescription patterns of antihypertensive drugs in the study population}

The most frequently prescribed class of antihypertensive drugs at the time of the visit was the ACEls at $48 \%$ followed by thiazide diuretics at $40 \%$ as shown in Table 2 .

Table 2: Antihypertensive medicines prescribed for hypertensive patients

\begin{tabular}{lll}
\hline Class $\backslash$ Drug & Frequency & \% \\
\hline ACEls & $\mathbf{1 1 9}$ & $\mathbf{4 8 . 2}$ \\
Enalapril & 119 & 48.2 \\
\hline ARBs & $\mathbf{6 7}$ & $\mathbf{2 7 . 1}$ \\
Losartan & 66 & 26.7 \\
Telmisartan & 1 & 0.4 \\
\hline CCBs & $\mathbf{6 4}$ & $\mathbf{2 6 . 0}$ \\
Nifedipine & 29 & 11.7 \\
Amlodipine & 35 & 14.3 \\
\hline BBs & $\mathbf{7 1}$ & $\mathbf{2 8 . 7}$ \\
Atenolol & 64 & 25.9 \\
Carvedilol & 4 & 1.6 \\
Propranolol & 3 & 1.2 \\
\hline Thiazide diuretics & $\mathbf{1 0 0}$ & $\mathbf{4 0 . 5}$ \\
Hydrochlorthiazide & 100 & 40.5 \\
\hline Other diuretics & $\mathbf{1 2}$ & $\mathbf{4 . 8}$ \\
Furosemide & 7 & 2.8 \\
Spironolactone & 5 & 2.0 \\
\hline Miscellaneous & $\mathbf{4}$ & $\mathbf{1 . 6}$ \\
Methyldopa & 2 & 0.8 \\
Hydralazine & 2 & 0.8 \\
\hline
\end{tabular}

NB: ACEls= Angiotensin converting enzyme inhibitors, ARBs $=$ Angiotensin receptor blockers, $B B s=\beta$ blockers, $\mathrm{CCBs}=$ Calcium channel blockers

The antihypertensive regimens prescribed are shown in Table 3 . ACEls were the most frequently prescribed monotherapy regimen, where they accounted for $20 \%$ of all prescriptions. A combination of an ACEl and a thiazide diuretic was the second most prescribed regimen at $14 \%$ of all prescriptions. 
Most patients were either on monotherapy or on two-drug regimens at $40 \%$ and $44 \%$ respectively. Combination therapies accounted for approximately $60 \%$ of all prescriptions.

Table 3: Specific regimens of antihypertensive drugs prescribed for the hypertensive patients

\begin{tabular}{lll}
\hline Regimen & Frequency & \% \\
\hline Monotherapy & 50 & 20.2 \\
ACEI & 21 & 8.5 \\
ARB & 11 & 4.5 \\
Beta blocker & 9 & 3.6 \\
Thiazide diuretic & 8 & 3.2 \\
CCB & & \\
& & \\
\hline 2-drug combination therapy & 35 & 14.2 \\
Thiazide diuretic + ACEI & 15 & 4.9 \\
Thiazide diuretic + BB & 12 & 4.5 \\
CCB + ACEl & 12 & 2.4 \\
Thiazide diuretic + ARB & 11 & 14.2 \\
CCB + ARB & 6 & 4.9 \\
CCB + Thiazide diuretic & 6 & \\
CCB + BB & & \\
& & 2.8 \\
\hline 3-drug combination therapy & 7 & 2.8 \\
BB + Thiazide diuretic + ACEI & 7 & 2.0 \\
BB + Thiazide diuretic + ARB & 5 & 1.2 \\
CCB + BB + Thiazide diuretic & 3 & 1.2 \\
CCB +ACEl + Thiazide diuretic & 3 & 0.8 \\
CCB + BB + ACEl & 2 & 0.8 \\
CCB + ARB + Thiazide diuretic & 2 & \\
CCB + BB +ARB & &
\end{tabular}

NB: $A C E I=$ Angiotensin converting enzyme Inhibitor, $A R B=$ Angiotensin receptor blocker, $B B=$ Beta blocker, $\mathrm{CCB}=$ Calcium channel blocker

Prescription patterns of co-medications to the hypertensive patients are shown in Table 4. Metformin and glibenclamide were the most common at $29 \%$ and $23 \%$ respectively.

Table 4: Co-medications prescribed for the hypertensive patients

\begin{tabular}{lll}
\hline Class/ Drug & Frequency & $\%$ \\
\hline Antidiabetics & & \\
$\quad$ Metformin & 71 & 28.7 \\
$\quad$ Glibenclamide & 57 & 23.1 \\
$\quad$ Insulin & 13 & 5.3 \\
$\quad$ Glimepiride & 1 & 0.4 \\
Statins & & \\
$\quad$ Atorvastatin & 11 & 4.4 \\
Antiplatelets & & \\
Aspirin & 22 & 8.9 \\
NSAIDs & 14 & 5.7 \\
Meloxicam & 1 & 0.4 \\
$\quad$ Diclofenac & 1 & 0.4 \\
$\quad$ Naproxen & & \\
Antiasthmatics & 2 & 0.8 \\
$\quad$ Salbutamol inhaler & 2 & 0.8 \\
$\quad$ Salbutamol tablets & 6 & 2.4 \\
Antihistamines & 8 & 3.2 \\
Antibiotics & 13 & 5.3 \\
Supplements & &
\end{tabular}

NB: NSAIDs= Non-steroidal anti-inflammatory drugs 


\subsection{Compliance of prescribing patterns to JNC-8 hypertension treatment guidelines}

Compliance to the JNC-8 treatment guidelines was high at $82 \%$ of prescriptions. Most prescribers complied with recommendations by the JNC- 8 report on the choice of antihypertensives for specific stages of hypertension, compelling indications, and use of appropriate concurrent medicines. For example, use of appropriate drug therapy for compelling indications met guideline requirements in all cases $(100 \%)$. For most prescribers, the rate of prescribing appropriate dosing and appropriate concurrent medicines was high at 96.4 and $95.4 \%$ respectively. However, compliance with treatment for stage 2 hypertension was $75.2 \%$ and for stage 1 lower at only $45.1 \%$.

\subsection{Control of blood pressure levels among hypertensive patients}

Overall, $46 \%$ of the hypertensive patients in the study attained adequate blood pressure control, i.e. BP below $140 / 90 \mathrm{mmHg}$ at the last clinic visit. There was typically a reduction in mean BP levels from diagnosis to the last clinic visit (Table 5). There was also a significant reduction in mean systolic blood pressure from $155 \mathrm{mmHg}$ at diagnosis to $141 \mathrm{mmHg}$ at the last clinic visit $(P<0.001)$. Similarly, the mean diastolic blood pressure was significantly reduced from $91 \mathrm{mmHg}$ at diagnosis to $83 \mathrm{mmHg}$ at the last visit $(P<0.001)$. There was also a significant reduction in the number of patients in all stages of hypertension at the last visit with 7\% having attained normal BP whereas those in stage 2 hypertension were significantly reduced from $43 \%$ to $19 \%$ at the last visit $(P<0.001)$.

Table 5: Control of blood pressure levels among hypertensive patients

\begin{tabular}{llll}
\hline Description & At Diagnosis & At the last visit & P value $^{*}$ \\
\hline $\begin{array}{l}\text { Systolic blood pressure (mmHg) } \\
\text { Mean (SD) }\end{array}$ & $155(20.4)$ & $141(20.5)$ & $<0.001$ \\
$\begin{array}{l}\text { Diastolic blood pressure (mmHg) } \\
\text { Mean (SD) }\end{array}$ & $91(10.7)$ & $83(10.5)$ & $<\mathbf{0 . 0 0 1}$ \\
& & & \\
Staging n (\%) & $0(0)$ & $18(7.3)$ & $<\mathbf{0 . 0 0 1}$ \\
$\quad$ Normal BP & $27(11.0)$ & $96(38.9)$ & \\
$\quad \begin{array}{l}\text { Prehypertension } \\
\text { Stage 1 hypertension }\end{array}$ & $115(46.5)$ & $86(34.8)$ & \\
$\quad$ Stage 2 hypertension & $105(42.5)$ & $47(19.0)$ & \\
& & & \\
Isolated Systolic Hypertension & $90(36.4)$ & $67(27.1)$ & $<\mathbf{0 . 0 0 1}$ \\
Stage 1 ISH & $58(23.5)$ & $43(17.4)$ & $<\mathbf{0 . 0 0 1}$ \\
Stage 2 ISH & $32(13.0)$ & $24(9.4)$ & \\
& & & \\
\hline
\end{tabular}

NB: $\mathrm{SD}=$ Standard deviation, $\mathrm{BP}=$ blood pressure, $\mathrm{n}=$ frequency

${ }^{*}$ The unpaired t-test was used for comparison of systolic and diastolic BP while chi-square test was used for comparison between the stages of hypertension

\subsection{Factors affecting blood Pressure control in hypertensive patients}

On bivariate analysis, some of the factors found to be significantly associated with poor BP control included the sex of the patient, the number of medicines they were prescribed and being on a beta blocker (Table 6). In the multivariable logistic regression analyses, all the included variables, except for being on beta-blockers, were independent risk factors for poor BP control. Females and patients on $\geq 2$ antihypertensive drugs were approximately two times more likely to have uncontrolled BP (OR: 2.3, $95 \% \mathrm{Cl}: 1.03,5.1, \mathrm{p}=0.043)$ and (OR:1.9, 95\% $\mathrm{Cl}: 1.1,3.3, \mathrm{p}=0.021)$, respectively. 
Table 6: Factors affecting blood pressure control in hypertensive patients

\begin{tabular}{|c|c|c|c|c|c|}
\hline Characteristic & $\begin{array}{c}\text { Total } \\
\mathrm{N} \\
\end{array}$ & $\begin{array}{l}\text { Blood pressure } \\
\text { controlled, } \\
\mathrm{n}(\%)\end{array}$ & $\begin{array}{l}\text { Blood pressure } \\
\text { uncontrolled, } \\
\text { n (\%) }\end{array}$ & $\begin{array}{l}\text { OR } \\
(95 \% \mathrm{Cl})\end{array}$ & $P$ value \\
\hline \multicolumn{6}{|l|}{ Sex } \\
\hline Male & 31 & $20(64.5)$ & $11(35.5)$ & 1 & \\
\hline Female & 216 & $94(43.5)$ & $122(56.5)$ & $2.4(1.1-5.2)$ & 0.028 \\
\hline \multicolumn{6}{|l|}{ Age } \\
\hline$<60$ years & 137 & $64(46.7)$ & $73(53.3)$ & 1 & \\
\hline$\geq 60$ years & 110 & $50(45.5)$ & $60(54.5)$ & $1.1(0.6-1.7)$ & 0.843 \\
\hline \multicolumn{6}{|c|}{ Treatment duration } \\
\hline 1 year & 63 & $30(47.6)$ & $33(52.4)$ & 1 & \\
\hline$>1$ year & 184 & $84(45.7)$ & $100(54.3)$ & $1.1(0.6-1.9)$ & 0.787 \\
\hline \multicolumn{6}{|c|}{$\begin{array}{l}\text { Number of } \\
\text { antihypertensives }\end{array}$} \\
\hline 1 & 100 & $57(57)$ & $43(43)$ & 1 & \\
\hline$\geq 2$ & 147 & $57(38.8)$ & $90(61.2)$ & $2.1(1.2,3.7)$ & 0.005 \\
\hline \multicolumn{6}{|c|}{ On a thiazide diuretic } \\
\hline Yes & 100 & $43(43)$ & $57(57)$ & $1.2(0.7-2.1)$ & 0.412 \\
\hline No & 147 & $71(48.3)$ & $76(51.7)$ & 1 & \\
\hline \multicolumn{6}{|l|}{ On a CCB } \\
\hline Yes & 64 & $27(42.2)$ & $37(57.8)$ & $1.2(0.7-2.2)$ & 0.460 \\
\hline No & 183 & $87(47.5)$ & $96(52.5)$ & 1 & \\
\hline \multicolumn{6}{|l|}{ On an ACEI } \\
\hline Yes & 119 & $60(50.4)$ & $59(49.6)$ & $0.7(0.4-1.2)$ & 0.195 \\
\hline \multirow{2}{*}{\multicolumn{6}{|c|}{ On an ARB }} \\
\hline & & & & & \\
\hline Yes & 67 & $25(37.3)$ & $42(62.7)$ & $1.6(0.9-2.9)$ & 0.089 \\
\hline No & 180 & $89(49.4)$ & $91(50.6)$ & 1 & \\
\hline \multicolumn{6}{|l|}{ On a BB } \\
\hline Yes & 71 & $25(35.2)$ & $46(64.8)$ & $1.8(1.1-3.3)$ & 0.028 \\
\hline No & 176 & 89 (50.6) & $87(49.4)$ & 1 & \\
\hline \multicolumn{6}{|l|}{ Diabetic } \\
\hline Yes & 91 & $41(45.1)$ & $50(54.9)$ & $1.1(0.6-1.8)$ & 0.791 \\
\hline No & 156 & $73(46.8)$ & 83 (53.2) & & \\
\hline
\end{tabular}

ACEl: angiotensin-converting enzyme inhibitor; ARB: angiotensin receptor blocker; BB - beta blocker; CCB: calcium channel blocker;

\subsection{Adherence to hypertension treatment guidelines by prescribers}

Five prescribers were interviewed of whom three were females aged 20 to 40 years (mean 30 years). This consisted of three medical officers, one clinical officer and one consultant physician treating 10 to 50 hypertensive patients per clinic day. Prescribers reported a great degree of awareness of the available hypertension treatment guidelines, namely JNC-7, JNC-8 and the Kenya Standard Treatment Guidelines (STG). All the prescribers had been trained on the use of the guidelines and appeared adherent. The most common challenges expressed by prescribers in the management of hypertension was poor patient adherence to medications, costly medications, medication stock outs, lack of patient counseling and support systems and the lack of laboratory and imaging facilities for further patient investigations.

\section{Discussion}

The demographic characteristics observed in this study were similar to those reported in other Kenyan studies $(23,39)$, with the high number of females (Table 1) thought to reflect better health seeking habits of females in general versus males (40). The mean age of 55.8 years (Table 1) is consistent with a previous study in Kenya (35). 
Diabetes was the most common comorbidity (Table 1), which was not surprising since hypertension and diabetes frequently coexist due to similar range of risk factors (19). This makes the management of hypertension extremely important in Kenya as poor BP control increases mortality in patients with diabetes (41).

Overall there was good compliance to treatment guidelines (JNC-8) at $82 \%$, mirroring a previous study in Kenya (20), which is encouraging. Deviations from the guidelines were mostly observed in the treatment of Stage 1 hypertension, where only $45 \%$ of patients were treated according to the recommendations of JNC-8. This could be due to clinical inertia (42) due to consideration of patients' circumstances including increasing the pill burden $(6,43,44)$. This will be followed up in future studies. Prescribers also pointed out a lack of laboratory and imaging facilities for further patient investigations, which could also impede appropriate intensification of therapy.

We believe the high use of ACEls (Table 2), and under use of CCBs (prescribed in only $26 \%$ of patients), can be attributed to prescribers applying the recommendations of the Kenyan STG rather than those of JNC-8, with most prescribers undergoing training of the Kenyan STGs and applying these in their clinical practice. The observed high use of thiazide diuretics (Table 2) is though consistent with current recommendations in the JNC guidelines, especially in black patients $(19,20)$.

Most patients were on monotherapy or 2-drug regimens (Table 3), with combination therapies accounting for approximately $60 \%$ of all prescriptions, similar to study carried out in India (45). The high rate of monotherapy could potentially be explained by prescribers' reluctance to intensify therapy due to a number of factors, similar to other studies (42), and will be explored further. We also observed that anti-diabetic drugs and low-dose aspirin were the most commonly prescribed concurrent medications (Table 4), no doubt due to the high prevalence of diabetes and CV disease among our hypertensive patients (Table 1), with aspirin recommended for secondary prevention of CV events in these patients (43).

However, despite good compliance with treatment guidelines, BP was controlled in less than half of the hypertensive patients in this study (Table 5), below WHO recommendations (46). This rate though is higher than that reported in other Kenyan studies (9, 23-25, 39), but similar to Zimbabwe (5), This is encouraging given concerns with the prescribing two or more anti-hypertensives and current high copayments for medicines for some patients. Even though adherence was not monitored in our study, most of our patients were on one or two-drug regimens, which could have promoted good adherence $(44,47)$. However, this could be at the expense of achieving adequate BP control.

Poor BP control in our study was strongly associated with sex whereby females were more likely to have poor control (Table 6), in contrast though to other African studies (1), despite potentially having better health seeking behaviour However, it should be noted that our study population was predominantly female with only a small proportion (13\%) male.

Other studies in Kenya have attributed poor BP control to old age, having diabetes and being on three or more drugs $(23,39)$. However, our study did not observe any association between poor BP control with age or diabetes, possibly because almost half of our patient population were below 60 years and did not have diabetes (Table 6). We observed though an association between multi-drug regimens and poor BP control. Twenty nine patients $(12 \%)$ in our study population were on a three- drug regimen (Table 3), with a high proportion $21(76 \%$ of these) being uncontrolled (data not shown). This could be explained by the difficulties patients face with adherence to multiple medications as observed in the study by Achieng et al (25). We also postulate that patients who needed multi-drug regimens could have had more severe, resistant or refractory hypertension, which is inherently poorly controlled (20). Poor BP control may also be due to underuse of CCBs and over use of ACEls and ARBs in our study patients (Table 3), with the ALLHAT study showing that both thiazide diuretics and CCBs have a greater effect on controlling BP versus ACEls in African Americans (36). Co-payments for multiple medicines could also be an issue affecting adherence rates (48-52). This should be helped by Access programmes in Kenya in the future $(31,32)$

\section{Study Limitations}

We acknowledge that the retrospective data used for this study obtained from patients' records may not always be accurate and complete. In addition, we only used one study site, which may not be totally 
representative of other MOPCs in Kenya. The actual protocol followed by healthcare professionals in the oscillometric measurement of patients' BP was also not outlined in patients' notes. Consequently, techniques may have varied among the professionals at this site, and we had no way of verifying this. In addition, only prescription and comorbidity data was used to examine compliance to treatment guidelines, which may not always be reliable.

Other factors which could affect the adequacy of BP control that were not considered include actual adherence to treatment in practice, accessibility to prescribed medicines, awareness and level of patient knowledge concerning the medicines prescribed, the need for proper BP control as well as other demographic characteristics such as the level of education and socioeconomic status. Furthermore, the small number of healthcare providers at the facility, with each attending to many patients, does mean that individual provider practices can significantly influence the overall standard of care observed at the facility. These factors will be addressed in future studies. Nevertheless, we believe our study is a good basis for suggesting future initiatives to improve the management of patients with hypertension in Kenya given the growing prevalence rates alongside the recent Access programmes.

\section{Conclusion and recommendations}

Prescribing patterns of antihypertensive drugs in this study were consistent with the Kenyan STGs, where most patients were on ACEls and thiazide diuretics. Compliance to the latest treatment JNC guidelines was also found to be reasonably high in this MOPC, though there were deviations in the treatment of stage 1 hypertension. This high level of compliance to treatment guidelines could contribute positively to BP control although an appreciable number of patients were still not adequately controlled, especially female patients. However, the observed gap in adherence to guideline recommendations provides an avenue for future interventions. Incongruences noted between recommendations in international guidelines (JNC 7 and 8) and the local Kenyan guidelines should also be remedied through the timely updating of local STGs to avoid confusion and improve future care. Confusion has been seen in other settings and countries when there is conflicting advice, and should be avoided if possible (53). Treatment guidelines should be reviewed to reflect for instance the growing evidence showing superiority of chlorthalidone over hydrochlorthiazedine $(54$, 55), although others are less sure (56). We will be monitoring this in the future.

Issues of co-payment may have impacted on the number of medicines prescribed and hence adequate control. However, it is difficult to substantiate this without further studies. Co-payments could be reduced following the Access initiatives, and this will be monitored further in this MOPC and other sites in Kenya. These schemes can also include training healthcare workers to provide appropriate care. Additional research is also needed to address other possible determinants of BP control such as medication adherence, which was not the subject of this research.

In the meantime, regular training of health workers on appropriate treatment guidelines is recommended to keep them up to date with current trends as new evidence emerges including addressing issues of poor BP control when this occurs. Active implementation programs have helped reduce BP among patients in Kenya. This alongside continuing audits on the use of antihypertensive medicines among treatment clinics is necessary to improve future care given the high and growing prevalence of hypertension in Kenya. We are encouraged by publications showing improvements in BP control in countries that have instigated multiple policies over time. This includes the USA with the percentage of adults with controlled BP increasing from $31.5 \%$ in 1999 to $54.0 \%$ in 2014 (57), with a similar increase in Turkey (58),

\section{Expert Commentary}

The prevalence of hypertension, and current poor control, is a major public health concern in Kenya. This is not helped by concerns with knowledge among patients, treatment approaches and adherence rates in routine care for ambulatory patients. This study showed there was generally good compliance with JNC guidelines, which is encouraging. However, the contradictory advice in the current Kenyan STGs has led to higher use of ACEls and lower use of CCBs. There are also an appreciable number of patients with uncontrolled BP, despite good adherence to the guidelines, due to a number of factors including potential co-payments, prescriber reluctance to intensify therapy if needed, as well as potentially under utilization of CCBs. Co-payments as well as healthcare professional training is being addressed through the Access programmes, and we will be monitoring their impact in future years to 
help improve the management of patients with hypertension in Kenya. Potential improvements in electronic systems should also help, building on existing examples.

\section{Five year commentary}

It is likely that we will see improvements in the management of patients with hypertension in Kenya over the next five years with increasing access to medicines with the ongoing programmes to offer these at low prices to patients, as well as improved training of healthcare professionals and patients and better access to laboratory and imaging facilities. This includes addressing fears of dose and drug escalation if needed to achieve good control. It is also likely there will be improvements in electronic systems to better monitor the care of hypertensive patients. This will build on existing initiatives such as the AMPATH approach for HIV patients with or without concomitant hypertension, enhanced by ongoing Access programmes. In addition, more up-to-date and consistent Standard Treatment Guidelines in Kenya addressing current concerns. These combined factors, together with regular visits to ambulatory care clinics, will help to improve the management of patients with hypertension in Kenya especially among women. As a result, there should be appreciable reductions in the number of patients with uncontrolled hypertension in Kenya over the coming years, similar to other countries in recent years.

\section{Key points}

- Hypertension is a major issue across Africa, including Kenya, leading to high rates of avoidable morbidity and mortality

- Prevalence rates as high as $55 \%$ have been observed in some populations in Kenya. In addition, the limited number of studies to date have shown limited control of hypertension, ranging from $3 \%$ to $33 \%$ of the adult population

- In this study, there was good adherence to the JNC guidelines (82\% of prescriptions), although there was high use of ACEls and under-utilisation of CCBs. This may have contributed to lower than expected control of BP in only $46 \%$ of patients despite the high adherence rates to the guidelines

- Limited intensification of therapy, possibly due to physician fears, as well as issues of copayments, may also have resulted in limited control of hypertension in practice in this study population

- It is expected that the introduction of Access programmes in Kenya, helping to address issues of co-payments and physician training, as well as improved electronic systems, will help improve the management of hypertension in Kenya in the future. This will be monitored.

\section{Acknowledgments and conflicts of interest}

There was no external funding for this project and none of the authors have any conflicts of interest to declare

\section{References}

1. Kayima J, Wanyenze RK, Katamba A, Leontsini E, Nuwaha F. Hypertension awareness, treatment and control in Africa: a systematic review. BMC cardiovascular disorders. 2013;13:54.

2. Lloyd-Sherlock P, Beard J, Minicuci N, Ebrahim S, Chatterji S. Hypertension among older adults in low- and middle-income countries: prevalence, awareness and control. International journal of epidemiology. 2014;43(1):116-28.

3. Dzudie A, Kengne AP, Muna WF, Ba H, Menanga A, Kouam Kouam C, et al. Prevalence, awareness, treatment and control of hypertension in a self-selected sub-Saharan African urban population: a cross-sectional study. BMJ open. 2012;2(4).

4. Cois A, Day C. Obesity trends and risk factors in the South African adult population. BMC obesity. 2015;2:42. 
5. Goverwa TP, Masuka N, Tshimanga M, Gombe NT, Takundwa L, Bangure D, et al. Uncontrolled hypertension among hypertensive patients on treatment in Lupane District, Zimbabwe, 2012. BMC research notes. 2014;7:703.

6. Nielsen JO, Shrestha AD, Neupane D, Kallestrup P. Non-adherence to anti-hypertensive medication in low- and middle-income countries: a systematic review and meta-analysis of 92443 subjects. Journal of human hypertension. 2017;31(1):14-21.

7. Olack B, Wabwire-Mangen F, Smeeth L, Montgomery JM, Kiwanuka N, Breiman RF. Risk factors of hypertension among adults aged 35-64 years living in an urban slum Nairobi, Kenya. BMC public health. 2015;15:1251.

8. Werner ME, van de Vijver S, Adhiambo M, Egondi T, Oti SO, Kyobutungi C. Results of a hypertension and diabetes treatment program in the slums of Nairobi: a retrospective cohort study. BMC health services research. 2015;15:512.

9. Mathenge $\mathrm{W}$, Foster $\mathrm{A}$, Kuper $\mathrm{H}$. Urbanization, ethnicity and cardiovascular risk in a population in transition in Nakuru, Kenya: a population-based survey. BMC public health. 2010;10:569-.

10. Irazola VE, Gutierrez L, Bloomfield G, Carrillo-Larco RM, Dorairaj P, Gaziano T, et al. Hypertension Prevalence, Awareness, Treatment, and Control in Selected LMIC Communities: Results From the NHLBI/UHG Network of Centers of Excellence for Chronic Diseases. Global heart. 2016;11(1):47-59.

11. Kearney PM, Whelton M, Reynolds K, Muntner P, Whelton PK, He J. Global burden of hypertension: analysis of worldwide data. Lancet. 2005;365(9455):217-23.

12. WHO. A global brief on hypertension - silent killer, global public health crisis. World Health Day 2013. Available at URL:

http://apps.who.int/iris/bitstream/10665/79059/1/WHO DCO WHD 2013.2 eng.pdf?ua=1

13. Psaty BM, Lumley T, Furberg CD, Schellenbaum G, Pahor M, Alderman MH, et al. Health outcomes associated with various antihypertensive therapies used as first-line agents: a network meta-analysis. Jama. 2003;289(19):2534-44.

14. Van Spall HG, Shanbhag D, Gabizon I, Ibrahim Q, Graham ID, Harlos K, et al. Effectiveness of implementation strategies in improving physician adherence to guideline recommendations in heart failure: a systematic review protocol. BMJ open. 2016;6(3):e009364.

15. Boonstra E, Lindbaek M, Khulumani P, Ngome E, Fugelli P. Adherence to treatment guidelines in primary health care facilities in Botswana. Trop Med Int Health. 2002;7.

16. Francke AL, Smit MC, de Veer AJE, Mistiaen P. Factors influencing the implementation of clinical guidelines for health care professionals: A systematic meta-review. BMC Medical Informatics and Decision Making. 2008;8:38-.

17. Taba P, Rosenthal M, Habicht J, Tarien H, Mathiesen M, Hill S, et al. Barriers and facilitators to the implementation of clinical practice guidelines: A cross-sectional survey among physicians in Estonia. BMC health services research. 2012;12:455-.

18. Donnellan C, Sweetman S, Shelley E. Health professionals' adherence to stroke clinical guidelines: a review of the literature. Health policy (Amsterdam, Netherlands). 2013;111(3):245-63.

19. National High Blood Pressure Education P. The Seventh Report of the Joint National Committee on Prevention, Detection, Evaluation, and Treatment of High Blood Pressure. Bethesda (MD): National Heart, Lung, and Blood Institute (US); 2004.

20. James PA, Oparil S, Carter BL, Cushman WC, Dennison-Himmelfarb C, Handler J, et al. 2014 evidence-based guideline for the management of high blood pressure in adults: report from the panel members appointed to the Eighth Joint National Committee (JNC 8). Jama. 2014;311(5):50720.

21. MOMS. Ministry of Medical Services Kenya, Ministry of Public Health and Sanitation Kenya. Standard Treatment Guidelines for Management and Referral of Common Conditions at Levels 4-6: Hospitals. Pages 36-37. Available at URL: http://apps.who.int/medicinedocs/documents/s21000en/s21000en.pdf

22. Oti SO, van de Vijver S, Gomez GB, Agyemang C, Egondi T, Kyobutungi C, et al. Outcomes and costs of implementing a community-based intervention for hypertension in an urban slum in Kenya. Bull World Health Organ. 2016;94(7):501-9.

23. Mutua EM, Gitonga MM, Mbuthia B, Muiruri N, Cheptum JJ, Maingi T. Level of blood pressure control among hypertensive patients on follow-up in a Regional Referral Hospital in Central Kenya.

The Pan African Medical Journal. 2014;18:278.

24. Hendriks ME, Wit FWNM, Roos MTL, Brewster LM, Akande TM, de Beer IH, et al.

Hypertension in Sub-Saharan Africa: Cross-Sectional Surveys in Four Rural and Urban Communities.

PloS one. 2012;7(3):e32638. 
25. Achieng L, Joshi M, Ogola EN, Karari E. Adequacy of blood pressure control and level of adherence with antihypertensive therapy. East African medical journal 2009;86(11):499-506.

26. AMPATH. Leading with care. Available at URL: http://www.ampathkenya.org/ [

27. Keny A, Wanyee S, Kwaro D, Mulwa E, Were MC. Developing a National-Level Concept Dictionary for EHR Implementations in Kenya. Studies in health technology and informatics. 2015;216:780-4.

28. Subramanian S, Tangka F, Edwards P, Hoover S, Cole-Beebe M. Developing and testing a cost data collection instrument for noncommunicable disease registry planning. Cancer epidemiology. 2016;45 Suppl 1:S4-s12.

29. Were MC, Mamlin BW, Tierney WM, Wolfe B, Biondich PG. Concept dictionary creation and maintenance under resource constraints: lessons from the AMPATH Medical Record System. AMIA Annual Symposium proceedings. AMIA Symposium. 2007:791-5.

30. Subramanian S, Kibachio J, Hoover S, Edwards P, Amukoye E, Amuyunzu-Nyamongo M et al Research for Actionable Policies:: implementation science priorities to scale up non-communicable disease interventions in Kenya. Journal of Global Health,. 2017; 7(1). Available at URL:

http://jogh.org/documents/issue201701/jogh-07-010204.pdf

31. Novartis. Kenya first country to launch 'Novartis Access', expanding affordable treatment options against chronic diseases. Oct 15 2015. Available at URL:

https://www.novartis.com/news/media-releases/kenya-first-country-launch-novartis-accessexpanding-affordable-treatment

32. Ogola E. Health Heart Africa - the Kenyan Experience. Available at URL:

http://www.pascar.org/uploads/files/HEALTHY HEART AFRICA Elijah Ogola.pdf

33. MoH. Republic of Kenya Ministry of Health. KENYA NATIONAL STRATEGY FOR THE

PREVENTION AND CONTROL OF NON-COMMUNICABLE DISEASES 2015 to 2020. Available at

URL: http://www.who.int/nmh/ncd-task-force/kenya-strategy-ncds-2015-2020.pdf

34. Cochran W. Sampling Techniques, 3rd Edition. 1977. ISBN: 978-0-471-16240-7. Available at URL: http://eu.wiley.com/WileyCDA/WileyTitle/productCd-047116240X.html [

35. Mwangi K. Prescription patterns in management of hypertension at Kenyatta National Hospital's Medical Outpatient Clinic. Available at URL:

http://uonlibrary.uonbi.ac.ke/content/prescription-patterns-management-hypertension-kenyattanational-hospitals-medical-outpatie-1

36. Wright JT, Probstfield JL, Cushman WC, Pressel S, Cutler JA, Davis BR, et al. ALLHAT FINDINGS REVISITED IN THE CONTEXT OF SUBSEQUENT ANALYSES, OTHER TRIALS AND META-ANALYSES. Archives of internal medicine. 2009;169(9):832-42.

37. Finks S, Ripley TL. Sorting it out: what JNC 8 is and what it is not. Journal of managed care \& specialty pharmacy. 2015;21(2):110-2.

38. Stephan D, Gaertner S, Cordeanu EM. A critical appraisal of the guidelines from France, the UK, Europe and the USA for the management of hypertension in adults. Archives of cardiovascular diseases. 2015;108(8-9):453-9.

39. Joshi MD, Ogola E, Karari E, et al. Adequacy of blood pressure control and level of adherence with antihypertensive therapy. East Afr Med J. 2009;86:499-506.

40. Mufunda E, Albin B, Hjelm K. Differences in health and illness beliefs in zimbabwean men and women with diabetes. The open nursing journal. 2012;6:117-25.

41. Tight blood pressure control and risk of macrovascular and microvascular complications in type 2 diabetes: UKPDS 38. UK Prospective Diabetes Study Group. BMJ (Clinical research ed). 1998;317(7160):703-13.

42. Okonofua EC, Simpson KN, Jesri A, Rehman SU, Durkalski VL, Egan BM. Therapeutic inertia is an impediment to achieving the Healthy People 2010 blood pressure control goals. Hypertension (Dallas, Tex : 1979). 2006;47(3):345-51.

43. Mancia G, Fagard R, Narkiewicz K, Redon J, Zanchetti A, Bohm M, et al. 2013 ESH/ESC Guidelines for the management of arterial hypertension: the Task Force for the management of arterial hypertension of the European Society of Hypertension (ESH) and of the European Society of Cardiology (ESC). Journal of hypertension. 2013;31(7):1281-357.

44. Vrijens B, Antoniou S, Burnier M, de la Sierra A, Volpe M. Current Situation of Medication Adherence in Hypertension. Frontiers in pharmacology. 2017;8:100.

45. Khurshid F, Aqil M, Alam MS, et al. Antihypertensive Medication Prescribing Patterns In A University Teaching Hospital In South Delhi. IJPSR. 2012;3(7):2057-63.

46. Weinehall L, Ohgren B, Persson M, Stegmayr B, Boman K, Hallmans G, et al. High remaining risk in poorly treated hypertension: the 'rule of halves' still exists. Journal of hypertension.

2002;20(10):2081-8. 
47. Fernandez-Arias M, Acuna-Villaorduna A, Miranda JJ, Diez-Canseco F, Malaga G. Adherence to Pharmacotherapy and Medication-Related Beliefs in Patients with Hypertension in Lima, Peru. PloS one. 2014;9(12):e112875.

48. Eaddy MT, Cook CL, O'Day K, Burch SP, Cantrell CR. How Patient Cost-Sharing Trends Affect Adherence and Outcomes: A Literature Review. Pharmacy and Therapeutics. 2012;37(1):45-

55.

49. Sinnott SJ, Buckley C, O'Riordan D, Bradley C, Whelton $\mathrm{H}$. The effect of copayments for prescriptions on adherence to prescription medicines in publicly insured populations; a systematic review and meta-analysis. PloS one. 2013;8(5):e64914.

50. Barron J, Wahl P, Fisher M, Plauschinat C. Effect of Prescription Copayments on Adherence and Treatment Failure with Oral Antidiabetic Medications. Pharmacy and Therapeutics. 2008;33(9):532-53.

51. Barbui C, Conti V. Adherence to generic v. brand antidepressant treatment and the key role of health system factors. Epidemiology and psychiatric sciences. 2015;24(1):23-6.

52. Simoens S, Sinnaeve PR. Patient co-payment and adherence to statins: a review and case studies. Cardiovascular drugs and therapy. 2014;28(1):99-109.

53. Kibuule D, Mubita M, Naikaku E, Kalemeera F, Godman BB, Sagwa E. An analysis of policies for cotrimoxazole, amoxicillin and azithromycin use in Namibia's public sector: Findings and therapeutic implications. International journal of clinical practice. 2017;71(2).

54. Barrios V, Escobar C. Which thiazide to choose as add-on therapy for hypertension? Integrated blood pressure control. 2014;7:35-47.

55. Vongpatanasin W. Hydrochlorothiazide is not the most useful nor versatile thiazide diuretic. Current opinion in cardiology. 2015;30(4):361-5.

56. Dhalla IA, Gomes T, Yao Z, Nagge J, Persaud N, Hellings C, et al. Chlorthalidone versus hydrochlorothiazide for the treatment of hypertension in older adults: a population-based cohort study. Annals of internal medicine. 2013;158(6):447-55.

57. Yoon SS, Carroll MD, Fryar CD. Hypertension Prevalence and Control Among Adults: United States, 2011-2014. NCHS data brief. 2015(220):1-8.

58. Sengul S, Akpolat T, Erdem Y, Derici U, Arici M, Sindel S, et al. Changes in hypertension prevalence, awareness, treatment, and control rates in Turkey from 2003 to 2012. Journal of hypertension. 2016;34(6):1208-17. 